\title{
De que campo do jornalismo estamos falando?
}

\author{
Of what field of journalism are we talking about?
}

\section{RESUMO}

Pensar o campo do jornalismo como possuidor ou não de um estatuto científico próprio, menos ou mais dependente de arcabouços conceituais, metodológicos e teóricos de outros campos das ciências sociais e humanas, vem tornando-se, nos últimos anos no Brasil, uma questão de destaque na rotina acadêmica. As tentativas de demarcação desse campo científico como autônomo, porém, parecem ignorar as reflexões epistemológicas sobre o campo maior no qual está inserido, o da Comunicação. Este trabalho pretende analisar diferentes conceitos de campo empregados nesse debate, com críticas a impasses colocados (a) pelo uso indiscriminado desses conceitos e (b) pelo equívoco em reduzir o objeto de estudo do Jornalismo à prática da profissão ou em promover a fragmentação de seu objeto. Palavras-chave: campo científico, campo jornalístico, teoria do jornalismo, jornalismo, epistemologia

\begin{abstract}
To think of journalism as having, or lacking, its own theoretical status, somewhat dependant on conceptual and theoretical paradigms borrowed from the human and social sciences, has become an important issue for the academic discussions. Tentative demarcations of an autonomous scientific field of research for journalism seem to ignore the epistemological debate of the bigger field in which journalism is inserted, that of Communication. This article aims to analyze different concepts of field used in this debate criticizing (a) the indiscriminate use of these terms and (b) the equivocal effort to reduce the object of study of the Journalism to practices of profession or in promoting fragmentation of its object.
\end{abstract}

Keywords: scientific field, journalistic field, theory of journalism, journalism, epistemology

\footnotetext{
* Professora do Programa de Pós-Graduação em Jornalismo da Universidade Federal de Santa Catarina (UFSC). Doutora em Ciências Sociais/ Antropologia, pela PUC-SP.
} 


\section{CAMPO PROFISSIONAL, CAMPO CIENTÍFICO, CAMPO ACADÊMICO E CAMPO EPISTÊMICO}

P

ENSAR O CAMPO do jornalismo como possuidor ou não de um estatuto científico próprio, menos ou mais dependente de arcabouços conceituais e teóricos de outros campos das ciências sociais e humanas, vem tornandose, nos últimos anos no Brasil, uma questão de destaque na rotina acadêmica da área. Como ponto de sustentação mais frequente, recorre-se ao conceito de campo de Pierre Bourdieu.

Um campo é um espaço social estruturado, um campo de forças - há dominantes e dominados, há relações constantes, permanentes, de desigualdade, que se exercem no interior desse espaço - que é também um campo de lutas para transformar ou conservar esse campo de forças. Cada um, no interior desse universo, empenha em sua concorrência com os outros a força (relativa) que detém e que define sua posição no campo e, em conseqüência, suas estratégias (Bourdieu, 1997: 57).

Este conceito é inaugural para a compreensão das relações entre agentes sociais em sua atividade ou profissão, no que diz respeito a valores e disputas de poder aí envolvidos e, também, para refletir sobre as práticas sociais como lugares de produção simbólica. Por isso, campo político, campo intelectual, campo jurídico, campo artístico, e... campo científico e campo jornalístico. É na imbricação desses dois últimos que surgem alguns equívocos no debate atual sobre uma «ciência jornalística». Bourdieu (1997 e 2005), para apreender mecanismos das práticas dos jornalistas, define campo jornalístico como um microcosmo que tem leis próprias, marcado por sua posição no mundo global e pelas atrações e repulsas que sofre da parte de outros microcosmos. O sociólogo atenta para fatores mais internos à prática, e com isso, discute a autonomia ambígua e a dupla dependência do campo jornalístico em relação aos campos econômico e político e destaca a influência «incessantemente ampliada» do jornalismo, continuamente sujeito à pressão da lógica comercial, sobre os cidadãos comuns, sobre os próprios jornalistas e também sobre os demais campos sociais - o das ciências sociais, os outros campos científicos, e com ainda mais força sobre o campo cultural, dos artistas e escritores.

Quanto ao conceito de campo científico, Bourdieu (1983: 122-155) o define como o lugar de disputas pela autoridade científica, resultante da combinação entre competência técnica e poder político. Logo, a posição de cada um no campo seria ao mesmo tempo uma posição científica e política. Immacolata Lopes e Fuentes Navarro (2005: 9), ao discutirem a epistemologia da Comunicação, também sublinham que o conhecimento científico resulta sempre de condições concretas para sua produção, condições de ordem científica, institucional e 
social. Não se pode ignorar, no entanto, que o conceito de campo científico de Bourdieu, como lembra Martino (2006), se localiza nos marcos da sociologia da ciência, com o objetivo de entender como se configura a dinâmica da produção da ciência a partir dos vetores sociais, institucionais e científicos propriamente ditos, e como se movimenta o capital simbólico do discurso científico. É preciso dizer que não é suficiente se sustentar nesses conceitos de campo e campo científico para compreender como se dá a produção de conhecimento em Jornalismo.

Deveríamos começar percebendo diferenças entre as noções de campo científico e campo acadêmico. Enquanto campo científico engloba o conhecimento derivado das diferentes lógicas produtivas de diversas instituições que fazem pesquisa científica, tanto governamentais como empresariais, campo acadêmico diz respeito à produção de conhecimento dentro das universidades, no contexto da pós-graduação, do ensino e mesmo da extensão (em Jairo Ferreira, 2007 e 2004, também encontramos a diferenciação entre campo acadêmico e campo epistemológico). Em meio às condições institucionais e políticas específicas do universo da academia, que agem a fortiori sobre os processos e resultados da produção da ciência, deveríamos focar a discussão no conceito de campo epistêmico para expressar com mais clareza qual o conhecimento jornalístico a que nos referimos. Campo epistêmico diz respeito a investimento conceitual, metodológico e teórico. Esses campos convivem no regime das interseções. O campo epistêmico tem, ou deveria ter, lugar demarcado nas práticas científicas que se dão na ambiência acadêmica, incluindo aí o que a academia tem feito para além do conhecimento resultante do que entendemos tradicionalmente por ciência, ou seja, também no conhecimento produzido pelos estudos das artes e da filosofia. A questão é mais intrincada do que apenas opor duas visadas sobre o campo científico, um conceito sociológico versus uma reflexão epistemológica (como sugere Martino, 2006).

Fuentes Navarro (2003: 20), ao analisar a construção de um marco epistemológico para a Comunicação, acentua que não podemos nos esquecer dos fatores sociopolíticos que, em diferentes escalas, determinam as análises epistemológicas dos saberes que postulamos como válidos - saberes científicos, submetidos tanto às condições da racionalidade como às do poder. Logo, os conflitos epistemológicos seriam, inseparavelmente, políticos. Difícil hoje alguém negar tal inseparabilidade, seja em qualquer disciplina científica, inclusive nos estudos da Comunicação, principalmente por aquele pesquisador que se dedica à investigação epistemológica - porque a legitimidade científica vem dessa imbricação entre a institucionalização cognoscitiva - conceitos, métodos, teorias - e a institucionalização político-social - programas, publicações, associações, fomentos etc (Fuentes Navarro, 2003: 18). Porém, se 
quisermos levar adiante a ideia de alguma cientificidade na pesquisa em Jornalismo, ajuda se considerarmos a distinção conceitual entre os campos social, científico, acadêmico e epistêmico. Parece correta a observação de L. C. Martino (2006: 34-41) quanto às imprecisões do conceito genérico campo - no caso, campo comunicacional - quando esta opção surge como fuga, quando se quer escapar da problemática em se empregar os conceitos de ciência ou disciplina científica.

Para o autor, outra motivação, muito menos neutra, também leva à opção pelo conceito de campo comunicacional ou campo da comunicação. Diz respeito ao sentido de campo em favor da natureza não disciplinar para o saber comunicacional, considerando a transdisciplinaridade como novo paradigma epistemológico. $\mathrm{O}$ artigo não vai se deter aqui na questão do campo comunicacional. Porém, irá ressaltar o movimento inverso que ocorre no debate acadêmico sobre jornalismo. Ou seja, enquanto na Comunicação a posição mais comum ignora ou recusa uma definição disciplinária, fundamentada no debate contemporâneo sobre ciências pós-modernas, no caso do Jornalismo a discussão inclina-se para a disciplinarização, para o esforço em consolidá-lo como «ciência jornalística» (ver Groth em Belau, 1966 e em Berger, 2007). Na Comunicação, haveria um descompasso entre a consolidação progressiva do campo institucional e a falta de autonomia do campo epistemológico (Caparelli e Stumpft, 2005: 67). Ou então, em análise discordante, um paradoxo aparente, com concomitância entre a "institucionalização da especificidade do campo acadêmico" da Comunicação, de sua autonomia institucional, e a "afirmação de um estatuto teórico transdisciplinar", sua demarcação epistemológica (Lopes, 2003: 290).

É visível o fortalecimento do Jornalismo como campo científico-institucional nos últimos cinco anos no país (ver a ainda recente criação da Associação Brasileira de Pesquisadores em Jornalismo - SBPJor) e de revistas acadêmicas, linhas e núcleos de pesquisa e programa de pós-graduação especializado em jornalismo etc.). Compassada com a institucionalização de seu campo científico, segue a especificidade da reflexão acadêmica, na direção da disciplinarização, para a defesa de um território delimitado para a produção e reprodução do saber jornalístico. De modo oposto à centrifugação verificada na antidisciplina / transdisciplina Comunicação (ver Martino, 2003 e 2006; Fuentes Navarro, 2003), ocorre nesse movimento centrípeto da potencial disciplina Jornalismo, aqui afirmo paradoxalmente, um afastamento de qualquer abordagem epistemológica - que é fundamental quando se pretende pensar a Teoria do Jornalismo ou o Campo Jornalístico. Mesmo assim, resulta no Jornalismo algo já detectado na grande área com relação ao trato epistemológico: fuga planejada, recusa 
presunçosa, desprezo arrogante, deslumbramento vaidoso, vontade de poder, esquecimento displicente, esforço inconsequente, desconfiança prudente; o elogio da errância (J. Machado da Silva, 2002) versus a crítica ao discurso da desobrigação e à preguiça teórica (W. Gomes, 2003); a necessidade de resposta à obrigação teórica versus a preocupação em atender a demandas organizacionais e profissionais imediatas. Muito disso se deve a mal-entendidos na reflexão sobre o campo.

Acrescenta pouco à consolidação da Teoria do Jornalismo, de sua episteme própria, observar obsessivamente a constituição institucional do campo, seus avanços no decorrer da história. John D. Peters (citado por Fuentes Navarro, 2003: 24; 30-31) questiona a pertinência de qualquer análise do discurso contemporâneo na área que não considere o plasma germinal conceitual malformado e indiferenciado da Comunicação, infestado de lugares-comuns. Entre as razões da malformação, Peters critica o fato de ser a institucionalidade da disciplina, e não a argumentação teórico-intelectual, o lugar de articulação do saber na Comunicação - «a autorreflexão como apologética institucional» explicaria também «a pobreza intelectual» do campo, revelando a atitude de «negociar alcance teórico por território acadêmico». Vale o mesmo para o Jornalismo. Com resultado igual ao apontado por Fuentes Navarro: confundir as condições de desenvolvimento do mercado profissional com as exigências de constituição do campo intelectual e, consequentemente, basear sua legitimação menos na competência acadêmica do que em sua competitividade institucional.

É problemático, então, também na investigação do jornalismo, tratar de questões epistemológicas recorrendo à sociologia da ciência, pensando que o conceito de campo jornalístico de Bourdieu possa responder pela episteme do jornalismo. Nem tampouco a combinação dos dois conceitos, campo jornalístico e campo científico, atende às lacunas do campo jornalístico em sua perspectiva epistemológica. Quadro que se complica, nas pesquisas, com o uso também indiscriminado do conceito de campo jornalístico como campo profissional, este último claramente um entre outros campos sociais. "Optando por uma abordagem propriamente sociológica, deslocam a questão do conhecimento pela do poder e não vêm nada mais que a luta fratricida pela conquista do reconhecimento, do status e do poder" (Martino, 2007: 25). Quando se trata de pensar a produção do conhecimento em jornalismo, deveríamos nos voltar mais criteriosamente para os conceitos de campo científico-acadêmico até chegar ao campo epistêmico, trabalhando na margem da autonomia epistemológica frente às dependências político-institucionais do campo científico, de maneira a investir no capital intelectual-cognitivo tanto quanto se vem investindo no capital político-institucional (Bourdieu, 2004). Seria preciso sair 
dos impasses sugeridos, em várias reflexões, sobre as variações: conhecimento do jornalismo, «no» jornalismo, «para» o jornalismo, «sobre» o jornalismo, «estudos de» jornalismo e «teorias do» jornalismo (E. Meditsch, 1997 e 1992; C. Franciscato, 2008; E. Machado, 2004). Esse tipo de abordagem procura a especificidade do Jornalismo com base em uma estratégia bem definida: vê na prática profissional o certificado científico do campo, ou seja, o conhecimento científico do jornalismo desvendado desde as demandas internas de aperfeiçoamento da prática. Para isso, faz-se uma ruptura duvidosa entre prática profissional, objeto científico e ensino do jornalismo, como se o objeto de estudo de uma pretendida ciência jornalística fosse assim fragmentado. E também a separação entre estudos «de» jornalismo, a partir de teorias e métodos de outras ciências sociais, e estudos «em» jornalismo, a partir da Teoria do Jornalismo; ou ainda entre «conhecimento de» (intuitivo, do cotidiano) e «conhecimento sobre» (sistemático e analítico). Quando não, entre Comunicação e Jornalismo, pretendendo a autonomia deste último - um fenômeno eminentemente comunicacional na abordagem desse artigo, no que tem de midiático, perspectiva relacional, interação social, ato comunicativo, troca, convencimento, sedução, poder..., muito embora com muitas especificidades como mídia adjetivada, noticiosa, que merece investigações, teorias e, a saber, métodos mais apropriados. A razão última dessas rupturas tem sido a prática em si mesma, o campo profissional, a materialidade dos produtos jornalísticos. Assim, define-se a atuação técnica profissional e os processos e produtos da rotina jornalística como locus único da teoria, que brotaria da prática.

Não facilita também analisar a questão conhecimento-jornalismo a partir da separação comunidade profissional (produto), academia (discurso) e setor produtivo (processo) (Franciscato, 2008). Não nos faz compreender mais os fundamentos do fenômeno comunicacional-jornalístico supor uma separação entre «sistematização gnosiológica (estudos midiológicos)» e «demandas de natureza empírica (estudos midiáticos)» (J. M. Melo, 2003: 111). Mesmo quando supõe o conjunto desses conhecimentos, a estratégia considera a soma das partes para chegar à totalidade do fenômeno jornalístico, mas a noção de um objeto de estudo íntegro se perde. Somar esses diversos saberes sobre o fenômeno jornalístico nos dá condições para compor um "pensamento jornalístico», tal como Bernard Miège fala em pensamento comunicacional: uma articulação de contribuições teóricas (conhecimento acadêmico) e contribuições da atividade profissional e social (conhecimento midiático), isto é, um pensamento que provém igualmente dos profissionais e dos atores sociais, ganhando forma tanto a partir da prática como de proposições teóricas (2000). Porém, é especificamente 
de contribuições teóricas sistematizadas que o presente artigo trata, do conhecimento que, como pesquisadores, produzimos para a compreensão do fenômeno jornalístico - e não dos saberes que a prática do jornalismo promove por ela mesma. Em Cenários, teorias e epistemologias da Comunicação, José Luiz Braga (2007) comenta diferentes ordens de saberes ou conhecimentos, entre elas a do mundo da experiência "(não "externamente" pensada, mas apenas exercida em suas incidências da prática do fazer), voltada para os objetivos direcionados da própria interação humana e social" e a de um exercício refletido "(gerando, portanto, pensamento observador e ideacional) subsumido a instâncias mais ou menos especializadas." No mesmo livro, Jairo Ferreira (2007) também discute diferenças entre conhecimento produzido socialmente e academicamente, este último o pensamento reflexivo abstrato.

\section{PARA ABRIR O JORNALISMO}

O investimento conceitual, metodológico e teórico, aquele trabalho epistêmico para dizer do que se trata a Teoria do Jornalismo, requer alguns enfrentamentos. De saída, romper com o espontaneísmo, ver além da prática, enfrentar o «obstáculo epistemológico». Quando o olhar restringe-se à prática jornalística, à expressão material de objetos específicos de pesquisa, impossibilita o afastamento necessário para enxergar o objeto de estudo do campo epistêmico do Jornalismo - inclusive impede fazer a própria crítica ao fenômeno, girando apenas em torno de descrições de produtos ou rotinas produtivas ou se sustentando na análise histórica de suas instituições (associações, revistas científicas, programas de pós-graduação, linhas de pesquisa, produção em congressos). "A identidade do campo não pode ser dada apenas com base em um relato histórico sobre a emergência dele" (Martino, 2006: 46). Essas duas escolhas, se assim incentivadas, nos levam a dois arcabouços também já observados no campo maior da Comunicação: (1) ao enclausuramento de uma possível Teoria do Jornalismo nas Teorias da Notícia - o que na Teoria da Comunicação corresponderia, mutatis mutandis, a localizar o objeto de estudo nos processos midiáticos, e não na diversidade dos fenômenos comunicacionais; e (2) ao levantamento e classificações confusas da pesquisa sobre a pesquisa, sobre o que temos investigado nesta área no país.

Quanto ao primeiro: como o jornalismo é, com certeza, mídia - agregando dispositivos tecnológicos, linguagens e públicos -, isso tem dispensado muitos pesquisadores de maiores questionamentos sobre a natureza do fenômeno diferentemente do que acontece na discussão sobre o fenômeno comunicacional em geral, em que se critica o midiacentrismo em favor das conversações e interações (sociais e interpessoais), ou se defende a especificidade dos meios de 
comunicação coletivos configurados historicamente pela técnica e pelo mercado e, hoje, como centralidade da organização complexa de uma sociedade globalizada. Conforme discutimos em outro texto (G. Silva e F. Pontes, 2008), no Jornalismo, há um empirismo descritivo que ganha maior visibilidade em alguns tipos de investigação. Investigações que podemos localizar no universo das Teorias da Notícia, geralmente entendidas como aquelas circunscritas às técnicas, processos e produtos da rotina profissional. Por isso, grande parte das respostas para explicar o Jornalismo é metonímica, tomando a parte pelo todo. Elas enfatizam que o objeto do Jornalismo é o processo de produção da notícia - os critérios de noticiabilidade, o trabalho rotineiro do jornalista, a linguagem/ discurso jornalístico, as temáticas das coberturas - (Gomis, 1991; Souza 2002; e Traquina 2004). Ao considerar como sinônimos Teoria do Jornalismo e Teoria da Notícia (como faz Sousa 2004: 02), toma-se parte do objeto do Jornalismo como todo o objeto da Teoria do Jornalismo. Como resultado, as investigações descrevem muito, mas suas conclusões se dão numa perspectiva conteudística (ver essa crítica em F. Resende, 2008) ou trazem mais explicações sobre temas sociais ou lógicas administrativas e econômicas da prática profissional do que sobre qual o lugar e sentido do fenômeno público de oferecer e receber notícias. As pesquisas assim desenvolvidas contam, geralmente, com a falsa segurança de que a empiria do mundo prático da profissão, seja na forma de processos ou produtos, responde naturalmente pela teoria, sem precisar trabalhar o objeto de estudo, este sempre construído teoricamente. A naturalização do objeto, tanto na Comunicação como no Jornalismo, e mesmo em qualquer outro campo de investigação científica, mais encobre que desvela. O objeto de estudo do Jornalismo precisa, então, de recursos teóricos para ser apreendido e não pode ser aquele visto por uma percepção espontânea, imediata. Escapar do espontaneísmo não é fácil, nem para o ofício de sociólogo; "sua dificuldade é tanto maior pelo fato de não conseguir encontrar, em sua herança teórica, os instrumentos que lhe permitiriam recusar radicalmente a linguagem corrente e as noções comuns" (Bourdieu, Chamboredon e Passeron, 2005: 23). Tal obstáculo epistemológico não é menos árduo no ofício de estudar o jornalismo. Aqui também «a ilusão da transparência» leva ao «senso comum erudito». Mais grave ainda no caso do jornalismo não apenas porque sua matéria-prima constitui-se da informação coletada no senso comum e na opinião pública para uma coletividade de leigos leitores/telespectadores/ouvintes/internautas, mas porque muitos pesquisadores confundem o ofício de pesquisador-cientista com o ofício de jornalista, sem conseguir operar o «corte epistemológico» necessário para separar a interpretação científica das evidências do senso comum ou, no caso aqui, da prática profissional (Bourdieu, Chamboredon e Passeron, 2005: 
32-44, reafirmando a "ruptura epistemológica" e o "obstáculo epistemológico" de Bachelard). Se trabalhar como jornalista exige pensar contra os fatos, para ir do senso comum ao crítico (S. Moretzhon, 2007), atuar na pesquisa em jornalismo requer «combater em si próprio» o jornalista profissional, imerso na prática; melhor dizendo, exige enfrentar a apologia à profissão do jornalista nos empreendimentos epistemológicos - Bourdieu, Chamboredon e Passeron recorrem novamente a Bachelard, "todo químico deve combater em si o alquimista", para sugerir que também todo sociólogo deve combater em si o profeta social que em muitas situações é levado a encarnar. Isso porque, quando não encontram uma teoria propriamente científica, uns lançam-se impulsivamente em uma prática que pretende descobrir em si mesma seu próprio fundamento teórico, e outros tantos continuam se alimentando da tradição (2005: 37 e 39). No caso do Jornalismo, fundamentar-se na prática tem importado principalmente investigar suas mutações tecnológicas, como se o conhecimento das transformações da tecnologia explicasse por si o Campo do Jornalismo e seu objeto de estudo; e ater-se à tradição tem significado pesquisas normativas e do dever-ser do jornalismo, repetindo a ordem de cumprimento de regras textuais e de gêneros de escrita ou de princípios (atualidade, objetividade) e de procedimentos éticos da profissão (imparcialidade, verdade).

Quanto ao (2) levantamento e classificações confusas da "pesquisa sobre a pesquisa», sobre o que temos investigado na nossa área, preocupa também o caráter descritivo e metodologicamente descuidado com que se pretende classificar os segmentos pesquisados, como já discuti em outro trabalho (G. Silva, 2008). Com o propósito de explicitar o status científico do Jornalismo (M. Benetti Machado, 2004; E. Machado, 2004; E. Meditsch e M. Segala, 2005; e J. M. Melo, 2006), essas leituras sobre trabalhos em congressos, linhas de pesquisa e livros são de escopo abrangente. Vemos nesses levantamentos sobre a produção científica em Jornalismo um elenco de grupos que mistura tema, metodologia, técnica de coleta de dados e suporte tecnológico, sem distingui-los como categorias que são. Logo, vemos a classificação organizar as pesquisas em: análise do discurso, história do jornalismo, jornalismo digital, teorias da narrativa, jornalismo especializado, produção da notícia, recepção, teorias do jornalismo, ética jornalística, estudos da linguagem, jornalismo e educação, estudos da profissão, análise de coberturas, jornalismo popular/alternativo, novas tecnologias, crítica do jornalismo, ensino do jornalismo e outros, como correntes ético-social, técnico-editorial, político-ideológico e crítico-profissional. Essa não distinção - um emaranhado de categorias não misturáveis como temas, objetos de trabalho, paradigmas teóricos, opções metodológicas, especificidade tecnológica - dificulta a compreensão da problemática da investigação no 
Campo do Jornalismo. Essas divisões sem critério, sem método, são visíveis também na organização em alguns grupos de trabalho, núcleos de pesquisa e mesas de comunicações coordenadas nos congressos e encontros. Ali, além do que acabamos de ver, também encontramos uma separação regida pela lógica do suporte tecnológico (telejornalismo, radiojornalismo e, recentemente com ainda mais vigor, o webjornalismo), ou, então, pela clássica herança que separa os elementos do circuito tripartido: (a) produção/rotina $>$ (b) produto em circulação/mensagem/linguagens/discursos $>$ (c) consumo/recepção. Falar da pesquisa nesses termos diz alguma coisa da institucionalização do campo científico e muito pouco do que está se passando na pesquisa em Jornalismo, do ponto de vista metodológico, teórico e epistemológico.

Tampouco os livros publicados aqui sobre Teoria do Jornalismo têm contribuído para pensar o campo, uma vez que também repetem o que Martino vem criticando nos livros de Teoria da Comunicação (Martino, 2007). Não garantem um denominador comum de teorias para a área, não discutem as filiações dessas teorias jornalísticas dentro do campo da Comunicação ou as influências que recebem de outros campos teóricos, não demonstram suas particularidades, nem sequer questionam as limitações dessa episteme. Não se trata de encontrar a teoria geral ou o consenso. Depois de todas as reflexões que nos foram colocadas pelo paradigma do pensamento complexo e pelo debate da transdisciplinaridade (E. Morin, 1990; B. S. Santos, 2000; I. Wallenstein, 1996; F. Saintout, 2003), não só tem se mostrado inviável como também temeroso buscar ainda hoje uma teoria geral. Essa condição, porém, não nos desobriga de pensar a «questão geral», como recomendada por Braga (2002: 268), ou, em outros termos, estudar o objeto de estudo do Jornalismo, seu centro de gravidade, seu núcleo objetivável, seu núcleo epistêmico (G. Silva, 2009).

Trabalhar para a constituição do Campo do Jornalismo demandaria, ao mesmo tempo, mais pesquisa epistemológica, investigando como se consolidam e se superam os conceitos e as teorias, e mais apuro metodológico e acuidade teórica nas pesquisas particulares, principalmente nas de opção empírica, cujo esforço descritivo costuma esgotar-se em si mesmo - geralmente por tratar a materialidade empírica como o próprio objeto da pesquisa, cuja escolha é individual, mas que sabemos ser também este construído teoricamente e, por isso, deveria ser tomado como uma das manifestações do objeto de estudo do campo. Essa questão é aprofundada na proposta em se pensar, em outro texto, sobre a «imaterialidade do objeto de estudo do Jornalismo» (G. Silva, 2009) Não há problema em se investir em pesquisa aplicada, desde que evitemos reeditar a pesquisa administrativa. Aportes do pensamento crítico podem colaborar no entendimento do lugar que desejamos para a teoria, no enfrentamento de 
postulados positivistas e de declarações normativas para a formação e prática profissional. Redutor, porém, é desejar que o campo tenha como objeto "a natureza da prática em jornalismo" e que a "função» da pesquisa seja apenas "contribuir para o aperfeiçoamento do jornalismo enquanto prática social" (E. Machado, 2004). Ao debater os cursos de Teoria da Comunicação à luz do Jornalismo (em Ferreira, G. e Martino (orgs.), 2007), Martino observa que a teoria deve ser considerada como uma forma de ver as coisas e, portanto, de colocar problemas. Ela representaria uma tomada de distância da realidade imediata, a fim de formular - e não apenas de resolver - os problemas tal como eles aparecem na dimensão prática. "De onde se entende o desapontamento que a visão tecnicista acaba tendo com os cursos de teorias, que não correspondem ao anseio de ver as dificuldades da profissão amparadas em um corpus de informações úteis e soluções imediatas" (p.106). Esse desapontamento se traduziria, entre outras maneiras, em «tecnização» da teoria (confusão e substituição da teoria pelo saber técnico, pelo know-how).

O tecnicismo espera da teoria o que ela não pode oferecer, espera que ela cumpra a função análoga à função "ajuda" proporcionada pelos programas de informática (...) a teoria não deve ser vista como uma caixa de ferramentas, de onde se faz sair todos os tipos de sortilégios e panacéias para resolver os problemas profissionais (Martino em Ferreira, G. e Martino, 2007: 106).

Se for o caso de pretender chegar à natureza do objeto de estudo, seria à natureza do fenômeno jornalístico, apreendido não apenas como prática profissional, mas em sua integralidade, em sua configuração social, política, econômica, tecnológica, como discurso, narração, imaginário, técnica e manifestação cultural; como constituído e constituinte da vida em sociedade. Esse, outro enfrentamento, o de focar o objeto de estudo do Jornalismo, apurando conceitos, fundamentos e métodos, levando as pesquisas a concluírem para o Jornalismo, para somar resultados particulares e compor teorias. Mas para isso - na direção oposta à ideia de consolidar a Comunicação como disciplina a partir do «núcleo duro» de um domínio de conhecimento (Martino, 2001)-, teríamos de fazer abertura do próprio conceito de jornalismo, daquele que tem sido adotado nas chamadas teorias do jornalismo. De imediato, incorporando o processo histórico para dar conta de que a definição de jornalismo não é estática, como todas as construções conceituais, e que por isso o objeto de uma «ciência jornalística» não se reduz ao fenômeno jornalístico tal qual temos nos dias de hoje - hegemônico, apesar das diferenças culturais. Abrir o Jornalismo também no que diz respeito aos modos de reportar, a seus gêneros; «amolecer» os conceitos de notícia e de acontecimento jornalístico para que a Teoria do 
Jornalismo não seja reduzida ao estudo das hard news, do lide e sublide, do jornalismo «de referência», das editorias de status como economia e política, mas ampliada também para a compreensão das soft news, das matérias de cultura e arte, das reportagens do jornalismo literário, sensacionalista, gonzo e popular.

Uma concepção de notícia está além das possibilidades que uma abordagem descritiva pode lhe dar (G. Silva e F. Pontes, 2008). Deveríamos localizar o conceito de notícia dentro da Teoria do Jornalismo e, depois de problematizá-lo, elegê-lo como uma categoria central, assim como Adelmo Genro Filho (1987) fez com as categorias da singularidade e da particularidade ao tratar epistemologicamente o jornalismo. Categorias clássicas do jornalismo moderno - objetividade, imparcialidade, atualidade - não atendem à complexidade do processo comunicacional-jornalístico. $\mathrm{O}$ mesmo ainda precisa ser feito com relação ao conceito de acontecimento jornalístico. Haveria também de se buscar recursos teóricos para explicar ou compreender a diversidade das manifestações empíricas do objeto de estudo nomeado fenômeno jornalístico. Pode parecer contraditório, mas esses enfrentamentos promovem, ao mesmo tempo, o foco no objeto de estudo do campo epistêmico e a abertura para um conceito integral de objeto, aquele que não separa prática-produto e teoria, que trabalha a imaterialidade da matéria jornalística e a materialidade tanto do corpóreo quanto do abstrato. De qualquer modo, muito do trajeto já percorrido pela pesquisa em Comunicação facilita o empreendimento dos estudos em Jornalismo - negar a relação entre ambos retarda a tarefa, seja a negação empreendida por quem deseja demarcar um campo autônomo para uma ciência jornalística ou por aqueles que, mesmo argumentando pela possibilidade de um lastro epistemológico para a Comunicação, como Martino, se recusam a pensar o jornalismo como um saber comunicacional (em Ferreira, G. e Martino (orgs.), 2007: 108) e igualmente o reduzem a mera prática.

Há muito a ser feito para responder ao vazio da Teoria do Jornalismo, à sua precariedade conceitual e fragilidade teórica, à dificuldade de tratar uma relação de extrema intimidade da prática jornalística com o senso comum - antes mesmo de se pensar na "segunda ruptura epistemológica" de que fala Boaventura S. Santos para uma ciência pós-moderna - aquela que concebe o reencontro da ciência com o senso comum, dentro de uma nova "configuração cognitiva», em que tanto uma quanto o outro se superem a si mesmos para dar lugar a outra forma de conhecimento (B. S. Santos, 1989: 34-45). O Campo do Jornalismo e suas teorias e conceitos próprios resultam de cada artigo científico, dissertação e tese, e da metateoria (reflexões epistemológicas) em sua abrangência ou em microterritórios como, por exemplo, em jornalismo especializado, meios tecnológicos específicos, temas editoriais ou nas interfaces com a arte e as outras 
ciências. Talvez seja necessário trazer, juntamente com os conceitos de campo e campo jornalístico, os outros conceitos de Bourdieu vinculados à produção simbólica (capital, trocas, bens, violência, poder) que se dá dentro e entre os diversos campos, para assim entendermos melhor como a imprensa transita entre os campos sociais, a partir de seu poder de «fazer crer» e de "dar sentido ao mundo», e, com destaque, identificar qual a modalidade de saber que está em jogo nas investigações que fazemos sobre o conhecimento em jornalismo ${ }^{1}$. Lucien Sfez faz para a comunicação uma distinção entre episteme e forma simbólica, quando toma a comunicação por quatro ângulos: como episteme, prática, ideologia e forma simbólica. A comunicação se instalaria num continuum que vai do núcleo epistêmico, descritível, legível e interpretável, ao outro extremo, à forma simbólica, que "envolve a tal ponto os nossos pensamentos e os nossos atos que, em teoria, não podemos descrevê-la. (...) nem tudo é observável, visível e legível" (L. Sfez, 1994: 9-16). No caso do Jornalismo, parece que, do modo como este vem sendo estudado, a prática profissional engole a forma simbólica do fenômeno, por isso tão difícil chegarmos à sua episteme. Perguntar bem costuma levar às melhores respostas. $\mathbf{M}$

\section{REFERÊNCIAS}

BELAU, Angel Flaus. La ciencia periodística de Otto Groth. Pamplona, Espanha: Instituto de Periodismo de la Universidad de Navarra, 1966.

BERGER, Christa. Jornalismo na Comunicação. In: WEBER, M.H.; BENTZ, I.; HOHLFELDT, A. (orgs). Tensões e objetos da pesquisa em comunicação. Porto Alegre: Sulina, 2002.

BERGER, Christa; MAROCCO, Beatriz (orgs.). A Era Glacial do Jornalismo: teorias sociais da imprensa. Porto Alegre, Sulina, 2007.

BOURDIEU, Pierre; CHAMBOREDON Jean-Claude; PASSERON, Jean-Claude. Ofício de sociólogo: metodologia da pesquisa na sociologia. Petrópolis, RJ: Vozes, 2004 (1968).

BOURDIEU, Pierre. O campo científico. In: Bourdieu (Coleção Grandes Cientistas Sociais). São Paulo: Ática, 1983.

Sobre a televisão. Rio de Janeiro: Jorge Zahar, 1997.

Os usos sociais da ciência: por uma sociologia clínica do campo científico. São Paulo: Editora Unesp, 2004.

The political field, the social science field, and the journalistic field. In: BENSON, R.; NEVEU, E. Bourdieu and the journalistic field. Cambridge: Polity Press, 2005.

BRAGA, José Luiz (2002). Análises. In: WEBER, M.H.; BENTZ, I.; HOHLFELDT, A. (orgs.). Tensões e objetos da pesquisa em comunicação. Porto Alegre: Sulina/Compós.
1. Como exemplo do emprego dos recursos conceituais 'bourdieurianos' sobre a produção simbólica, lembro a pesquisa Campos em confronto: a terrae o texto (Christa Berger, 1998), que mostra bem a relação capital simbólico/ campo jornalístico. 
Introdução: pequeno roteiro de um campo não traçado. In: FERREIRA, Jairo (org.). Cenários, teorias e epistemologias da Comunicação. Rio de Janeiro: E-papers, 2007.

CAPARELLI, Sergio; STUMPF, Ida R.C. El campo académico de la comunicación, revisitado. In: LOPES, M.I.V.; FUENTES NAVARRO (comps.) Comunicación: campo y objeto de estúdio - perspectivas reflexivas latinoameriacanas. Guadalajara, México: UTESO; Universidad de Guadalajara; Aguascalientes, México: Universidad Autónoma de Aguascalientes; Colima, México: Universidad de Colima, 2005.

FAUSTO NETO, Antonio. A pesquisa vista "de dentro da casa" (ou reflexões sobre algumas práticas de construção de objetos de pesquisa em comunicação). In: WEBER, M.H.; BENTZ, I.; HOHLFELDT, A. (orgs.). Tensões e objetos da pesquisa em comunicação. Porto Alegre: Sulina/Compós, 2002.

FERREIRA, Jairo. Campo acadêmico e epistemologia da comunicação. In: LEMOS, A.; PRYSTON, A.; SILVA, J.; SÁ, S. (orgs.). Mídia.br: Livro da XII Compós 2003, Porto Alegre: Sulina/Compós, 2004.

(). Questões e linhagens na construção do campo epistemológico da comunicação. In: FERREIRA, Jairo (org.). Cenários, teorias e epistemologias da comunicação. Rio de Janeiro: E-papers, 2007.

FRANCISCATO, Carlos E. Desafios para pensar a geração de conhecimento no campo do jornalismo. Anais do XXXI Congresso Brasileiro de Ciências da Comunicação. Intercom - Sociedade Brasileira de Estudos Interdisciplinares da Comunicação. Natal, RN, 2 a 6 de setembro de 2008, 2008.

FUENTES NAVARRO, Raúl. La producción social de sentido sobre la producción social de sentido: hacia la construcción de um marco epistemológico para los estúdios de la comunicación. In: LOPES, M. I. V. (org.). Epistemologia da comunicação. São Paulo: Edições Loyola, 2003.

GENRO FILHO, Adelmo. O segredo da pirâmide: por uma teoria marxista do jornalismo. Porto Alegre: Editora Tchê, 1987.

GOMES, Wilson. O estranho caso de certos discursos epistemológicos que visitam a área da Comunicação. In: LOPES, M. I. V. (org.). Epistemologia da Comunicação. São Paulo: Edições Loyola, 2003.

GOMIS, Lorenzo. Teoría del periodismo: como se forma el presente. Barcelona: Paidós, 1991.

GROTH, Otto. Tarefas da pesquisa da ciência da cultura. In: BERGER, C; MAROCCO, Beatriz (orgs). A Era Glacial do Jornalismo: Teorias sociais da imprensa. Porto Alegre, Editora Sulina, 2007, pp. 182-306. Original publicado em 1961. Tradução de Luís Marcos Sander e Geraldo Korndörfer.

HOHLFELDT, Antonio; STRELOW, Aline (). Metodologias de pesquisa: o estado da arte no campo do jornalismo - os núcleos de pesquisa da Intercom. V Encontro Nacional 
de Pesquisadores em Jornalismo - SBPJor, Aracaju, Se, novembro de 2007, 2007.

LOPES, M. Immacolata Vassallo de. Sobre o estatuto disciplinar do campo da Comunicação. In: LOPES, M. I. V. (org.). Epistemologia da Comunicação. São Paulo: Edições Loyola, 2003.

LOPES, M. Immacolata Vassallo de; FUENTES NAVARRO (comps.). Comunicación: campo y objeto de estúdio - perspectivas reflexivas latinoameriacanas. Guadalajara, México: UTESO; Universidade de Guadalajara; Aguascalientes, México: Universidad Autónoma de Aguascalientes; Colima, México: Universidad de Colima, 2005.

MACHADO, Márcia Benetti. "Pesquisa em Jornalismo no Brasil: dados e reflexões sobre três ambientes". II Encontro Nacional de Pesquisadores em Jornalismo - SBPJor, Salvador, 2004.

MARTINO, Luiz Claudio. As epistemologias contemporâneas e o lugar da Comunicação. In: LOPES, M. I. V. (org.). Epistemologia da Comunicação. São Paulo: Edições Loyola, 2003.

Abordagens e representação do campo comunicacional. Comunicação, Mídia e Consumo. v. 3, p. 33-54. São Paulo, 2006.

De qual campo da comunicação estamos falando? In: WEBER, M.H.; BENTZ, I.; HOHLFELDT, A. (orgs.). Tensões e objetos da pesquisa em comunicação. Porto Alegre: Sulina, 2001.

Interdisciplinaridade e o objeto de estudo da comunicação. In: HOHLFELDT, A., MARTINO, L.C. e FRANÇA, V. V. (orgs.). Teorias da comunicação: conceitos, escolas e tendências. Petrópolis, RJ: Vozes, 2001.

Os cursos de teoria da comunicação à luz do jornalismo: obstáculos e impropriedades das posições tecnicista e intelectualista. In: FERREIRA, Giovandro M. e MARTINO, L. C. (orgs.). Teorias da Comunicação: epistemologia, ensino, discurso e recepção. Salvador: EDUFBA, 2007.

MARTINO, Luiz C.; BERGER, Charles; CRAIG, Robert T. Teorias da comunicação: muitas ou poucas? Cotia, SP: Ateliê Editorial, 2007.

MEDITSCH, Eduardo. Jornalismo como forma de conhecimento. Revista Brasileira de Ciências da Comunicação, da Intercom. Vol. XXI, nº 1, jan/jun 1998, p. 25-38. São Paulo.

O conhecimento do jornalismo. Florianópolis, SC: Ed. UFSC, 1992.

MEDITSCH, Eduardo; SEGALA, Mariana. Trends in three 2003/4 journalism academic meetings. Brazilian Journalism Research. Brasília, Br: SBPJor. v. 1, n. 1, semester 1, 2005. pp. 47-60, 2005.

MELO, J. Marques de (). Teoria do jornalismo: identidades brasileiras. São Paulo: Paulus, 2006.

Midiologia brasileira: o resgate das fontes paradigmáticas. In: Lopes, M. I. V. (org.). Epistemologia da Comunicação. São Paulo: Edições Loyola, 2003. 
MIÈGE, Bernard. O pensamento comunicacional. Petrópolis, RJ: Vozes, 2000 (1995).

Moretzohn, Sylvia. Pensando contra os fatos: jornalismo e cotidiano, do senso comum ao senso crítico. Rio de Janeiro: Revan, 2007.

MORIN, Edgar. Introdução ao pensamento complexo. Lisboa: Instituto Piaget, 1990.

RESENDE, Fernando. A narratividade do discurso jornalístico - a questão do outro. $6^{\circ}$. Encontro Nacional de Pesquisadores em Jornalismo / SBPJor, 2008. São Bernardo do Campo, SP, 2008.

SAINTOUT, Florencia (edit.). Abrir la comunicación: tradición y movimiento en el campo académico. La Plata, Argentina: Facultad de Periodismo y Comunicacón Social / Universidad Nacional de La Plata, 2003.

SANTOS, Boaventura de Souza. Introdução a uma ciência pós-moderna. Rio de Janeiro: Graal, 200o. (1989) 3a. ed.

SFEZ, Lucien. Crítica da comunicação. São Paulo: Edições Loyola, 1994, 1992.

SILVA, Juremir Machado da. Análises. In: WEBER, M.H.; BENTZ, I.; HOHLFELDT, A. (orgs.). Tensões e objetos da pesquisa em comunicação. Porto Alegre: Sulina, 2002.

SILVA, Gislene. Problemática metodológica em jornalismo impresso. XXXI Congresso da Intercom. Natal, RN, setembro de 2008.

SILVA, Gislene. Sobre a imaterialidade do objeto do Jornalismo. VIII Lusocom. Lisboa, Portugal, abril de 2009.

SILVA, Gislene; PONTES, Felipe. Teorias da notícia: impasses para uma Teoria do Jornalismo. $6^{\circ}$ Encontro Nacional de Pesquisadores em Jornalismo / SBPJor. São Bernardo do Campo, SP, novembro de 2008.

SOUSA, Jorge Pedro. Teorias da notícia e do jornalismo. Chapecó: Argos, 2002.

TRAQUINA, Nelson. Teorias do jornalismo: porque as notícias são como são - Vol. 1. Florianópolis: EDUFSC, 2004.

WALLENSTEIN, Immanuel et al. Para abrir as ciências sociais - Comissão Gulbenkian para a reestruturação das ciências sociais. São Paulo: Editora Cortez, 1996.

\section{Endereços eletrônicos:}

MACHADO, Elias. "Dos estudos sobre jornalismo às teorias do jornalismo (três pressupostos para a consolidação do jornalismo como campo de conhecimento)". e-compós revista eletrônica da Associação Nacional dos Programas de PósGraduação em Comunicação. Ed.1, dez 2004. Disponível em: <http://www.compos. org.br/e-compos>.

Artigo recebido em 7 de julho e aprovado em 24 de agosto de 2009 . 